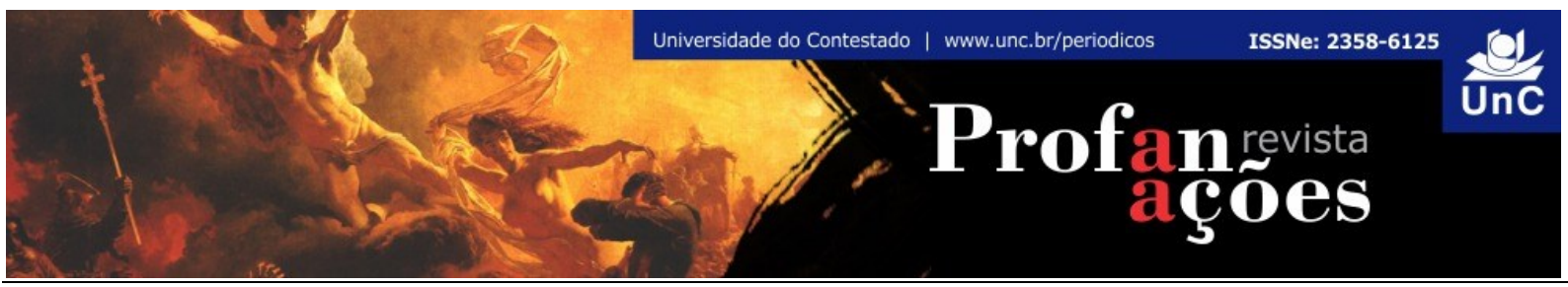

\title{
A AUTO-HETEROGRAFIA DE GIORGIO AGAMBEN: ESTUDO, ESTÚDIO E RETRATOS
}

Resenha do livro: AGAMBEN, Giorgio. Autoritratto nello studio. Milano: Nottetempo, 2017.

Luan Sevignanil

Una forma di vita che si mantiene in relazione con una una pratica poetica, quale che sia,

è sempre nello studio,

è sempre nel suo studio.

Giorgio Agamben

De antemão: não se trata de uma autobiografia, mas de uma "autoheterografia", como define o próprio autor. Não se trata de um "lessico famigliare" (tal qual Natalia Ginzburg), mas de um "tema iconográfico familiar", tão caro à história da pintura, tão mais caro a Aby Warburg. O recente livro de Giorgio Agamben é, antes de tudo, um livro de afetos: e afeto nesse caso, como já em Freud, está ligado às

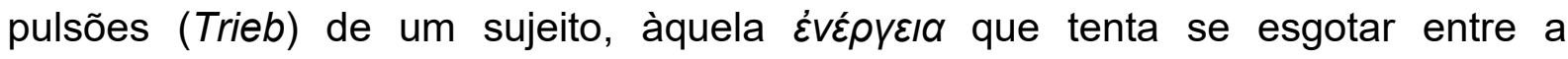
satisfação e o seu contrário.

$O$ recente livro de Giorgio Agambem é também um livro de encontros: com Heidegger, José Bergamín (ou Pepe), com Guy Debord (amigo tardio), Manganelli, Patrizia Cavalli, Caproni, Savinio (Ruggero, não Alberto), Morante, Nancy, Pasolini, Adorno, Gershom Scholem e tantas outras pessoas.

É, ainda, um livro de memórias: as de Walter Benjamin, de Simone Weil, de Claudio Rugafiori, de Hannah Arendt, Roberto Bazlen (ou Bobi, importante figura do

\footnotetext{
${ }^{1}$ Graduado em Letras e Literatura Vernáculas na Universidade Federal de Santa Catarina com mobilidade para La Sapienza Università degli Studi di Roma (2014), sob a orientação do Dr. Ettore Finazzi-Agrò. Bolsista do CNPq de 2012 a 2014, sob a orientação do Dr. Carlos Eduardo Schmidt Capela. Membro-pesquisador no Núcleo de Estudos Literários e Culturais - NELIC. Atualmente é mestrando em Filologia e Critica Letteraria na Università degli Studi di Trento (2016). Tem experiência na área de Letras Português e Italiano, com ênfase em Teoria Literária, Literatura Brasileira, Italianística e Literatura e Psicanálise. Università degli Studi di Trento. Itália. E-mail: sevignani.luan@gmail.com
}

Ano 4, n. 2, p. 235-240, jul./dez. 2017. 
Novecento italiano) $)^{2}$, Giovanni Urbani, Wilcock, Goethe, Sandro Penna, entre tantos outros.

Da mesma forma, "Autoritratto nello studio" é um livro de lugares: não apenas de seus escritórios - em Roma, próximo ao Cinema Farnese e ao Campo de' Fiori, no vicolo del Giglio; e em San Polo, em Veneza -, mas também de lugares dos quais o coração soube recordar: sua triste Roma da infância em contraste com a doce, mas pobre, Roma dos anos de formação universitária, junto a várias figuras de relevo; a Veneza de Giambattista Tiepolo, de seu ex-emprego na IUAV (Universidade de Veneza) e dos amigos mais caros; a Paris de Klossowski, mas também, vinte anos mais tarde, a Paris de Nancy. Ou, ainda, a Paris da Bibliothèque Nationale, onde descobrira, analisando as correspondências entre Bataille e Benjamin, os manuscritos inéditos do escritor alemão, na época, não catalogados pela biblioteca; a Espanha, das ensolaradas Andaluzia e Sevilha, e Madri, com os olhos de José Bergamín; Londres, em seus anos de pesquisa no Warburg Institute; ou mesmo em Ponza e na Toscana, lugares de descanso.

O recente livro de Agamben ressente-se de tempos: seus tempos de juventude em uma Roma "pré-histórica", subtraída à forma de "cidade vertical" ${ }^{3}$, se associam às imagens de sua infância e da universidade; mas continuemos: [...] ressente-se de tempos: daqueles anos em Paris, na rue Jacob 16 (de 1971 a 1974); dos anos recentes que, com Emanuele, Elenio e Nicoletta, Agamben tentou verificar a atualidade de um projeto de revista nunca feito (justamente aquele esboçado, em Paris, com Italo Calvino e Claudio Rugafiori, que se desdobraria, de certo modo, em "Categorias Italianas"); dos momentos na Provença, na companhia de Heidegger,

\footnotetext{
${ }^{2}$ Roberto Bazlen (1902-1965), de Trieste, foi um crítico literário, tradutor e editor. Participou de vários grupos intelectuais em Turim e Roma, desempenhando um importante papel na cultura italiana, tanto pelas traduções de Kafka, Musil e outros, quanto pela disseminação, ainda que recalcada pelo Fascismo e pela Igreja, da psicanálise na Itália.

${ }^{3}$ Em 2006, Giorgio Agamben concede uma entrevista a Roberto Andreotti e a Federico De Melis, na qual, ao ser perguntado sobre o nexo "vida" e "lugares", diz ter se divertido, na época, fazendo collages: recortando mapas de inúmeras cidades e sobrepondo-os a outras, criando uma espécie de cartografia existencial. A entrevista foi publicada no caderno Alias, um suplemento dominical do jornal "II Manifesto" (pp.3-4), podendo ser consultada em: https://haecceitasweb.com/2010/05/27/giorgio-agamben-un-ragionare-per-paradigmi/ (acesso em 30/09/17); a entrevista fora traduzida por Vinícius Nicastro Honesko e se encontra no blog "Flanagens", interessante fonte, em língua portuguesa, de assuntos relacionados a "Giorgio Agamben". Acesso: http://flanagens.blogspot.it/2016/01/as-lembrancas-por-favor-nao.html (acesso em 30/09/17).
} 
durante seus seminários (Le Thor, no final da década de 1960)4; em suma, destes vários tempos ora conectados ora somente articulados na escrita de si.

É um livro de objetos: quadros que reproduzem as pinturas de Tiziano; fotografias com a imagem de Herman Melville, uma sua com Heidegger, outra de José Bergamín, entre outras; dentre os inúmeros objetos, há cartas, cartões-postais (de Alfred Jarry, comprado numa das infinitas lojas de antiguidades de Paris); há um móvel japonês num de seus escritórios, uma marionete pulcinella (que já pertencera ao célebre ator napolitano, Totò); há livros, vários livros: La Société du Spectacle, de Debord, bem como uma primeira edição (1943) de /l principe infelice, de Tommaso Landolfi, seu livro preferido; em seus escritórios, há certamente seus cadernos que, entre outras coisas, figuram como um "laboratório de pesquisa" (AGAMBEN, 2015, p. 72), carregando seus pensamentos, citações, anotações, memórias e até mesmo lembranças de alguns sonhos; todavia, o objeto que mais chama a atenção, sobretudo para o público brasileiro, é sem dúvida uma fotografia de Sebastião Salgado, em que retrata a menina Joceli Borges, cujo nome é desconhecido ao filósofo, mas que, nela, em Joceli, ele vê eternizada a figura de quem irá Ihe julgar em seu último dia 5 .

O livro de Agamben é, ainda, um livro de citações: seus autores favoritos, poemas indeléveis, passagens citadas "de cor". Passages. De Caproni (recentemente objeto do Exame de Estado6, na Itália) a Patrizia Cavalli (poeta que publicou pela Quodlibet, em abril deste ano, "Flighty matters").

Autoritratto é um livro forte, na medida em que faz emergir um pouco da sua vida íntima, sempre tida pelo público italiano como discreta. Por isso, mas também pela quantidade de documentos e imagens, o livro requer intervalos.

\footnotetext{
${ }^{4}$ Interessante ressaltar o fato que em boa parte dos últimos livros de Agamben, isto é, desde "L'avventura" (Nottetempo, 2015), passando por "Che cos'è la filosofia" (Quodlibet, 2016) até "Karman: breve trattato sull'azione, la colpa e il gesto (Bollati Boringhieri, 31 de agosto de 2017), o autor salda seu débito com Heidegger quase como se, depois de tê-lo encontrado, não pudesse mais pensar sem ele. Seu encontro com o filósofo alemão é narrado e foto-contado detalhadamente em "Autorittrato nello studio".

${ }^{5}$ Diz Agamben: "Sull'estremità destra del tavolo di Venezia, è poggiata una fotografia di Salgado [...]. II suo nome mi è sconosciuto, ma so con certezza che sarà lei a giudicarmi nell'ultimo giorno, a condannarmi, come sembra suggerire la sua espressione sofferente e severa, o ad assolvermi" (AGAMBEN, 2017, p.76)

${ }^{6}$ Maturità ou Esame di Stato é uma prova feita pelo Estado, a fim de certificar que os alunos concluíram os estudos regulares, podendo ingressar na universidade.
} 
E é justamente no intervalo que ele opera. No intervalo de um afeto, entre Benjamin e Heidegger, sua "auto-heterografia", a escrita de si que se dá na escrita do outro, deixa entrever um balanço de uma vida de constantes atravessamentos culturais. Se, em intervalos, ora ditados por palavras ora por imagens, a vida de Agamben parece sempre continuar nas formas de vida que conta, também esta resenha, como forma de sobrevivência ulterior à sua leitura, poderia continuar; assim, esta resenha, como Agamben, também poderia não faltar aos encontros. Poderia estender os tempos. Poderia riscar os espaços. Poderia acrescentar memórias. Poderia atravessar afetos. Poderia, em suma, apenas continuar, como se continua uma leitura - mesmo que seja a leitura de um outro livro.

Diante disso, tenho apenas mais dois pontos a levantar: a recente "autohetorografia" de Giorgio Agamben é um tempo presente, que parece apontar para duas direções significativas:

1) para um passado, relembrando, por metonímia, a imagética Voyage autour de ma chambre, de Xavier de Maistre, uma vez que, assim como o protagonista francês, me parece que a "autoeterografia" do filósofo italiano coloca em operação um corpo que toca um objeto e cai no abismo de uma digressão, que é memória, lugares, tempos, objetos, citações;

2) parece apontar também para um futuro, ou melhor, para a imagem de um futuro possível. Diz Agamben:

\begin{abstract}
O que foi, para mim, o encontro com Heidegger, na Provença? Evidentemente, não consigo separá-lo do lugar, no qual aconteceu - seu rosto dócil e severo, os olhos tão brilhantes e inflexíveis não vi em nenhum outro lugar, senão em sonho. Existem, na vida, eventos e encontros tão decisivos, que é impossível que eles entrem completamente na realidade. Acontecem, claro, e marcam a vida - mas não acabam, por assim dizer, nunca de acontecer. Encontros, nesse sentido, contínuos, como os teólogos diziam: que Deus não para nunca de criar o mundo. Eles não cessam de nos acompanhar até o fim. Fazem parte daquilo que permanece incompleto em uma vida, que vai além dela. $E$ aquilo que ultrapassa a vida é aquilo que resta dela. (AGAMBEN, 2017, p.16-17)
\end{abstract}

\footnotetext{
${ }^{7}$ Che cos'è stato per me l'incontro con Heidegger in Provenza? Certo non riesco a separarlo dal luogo in cui è avvenuto - il suo viso insieme mite e severo, gli occhi così accesi e intransigenti non li ho visti altrove se non in sogno. Vi sono nella vita eventi e incontri a tal punto decisivi, che è impossibile che entrino completamente nella realtà. Accadono, certo, e segnano la vita - ma non finiscono, per così dire, mai di accadere. Incontri, in questo senso, continui, come i teologi dicevano che Dio non smette mai di creare il mondo. Essi non cessano di accompagnarci fino alla fine. Fanno parte di ciò che resta incompiuto in una vita, che va al di là di essa. $\mathrm{E}$ ciò che va al di là della vita è ciò che resta di essa. (AGAMBEN, 2017, p.16-17)
} 
Ou seja, seu encontro com Heidegger, durante os seminários de Le Thor, não é senão um acontecimento que não cessa de acontecer. Não apenas não cessa, como retorna, insistentemente, à memória do autor, seja sob uma forma de vida (Heidegger), seja sob a forma de lugar, que é também uma forma de vida, como se verá. E como memória que não cessa, algumas páginas depois, Agamben continua, afinal é de continuidade que se trata:

Muitos anos depois, em 1985, voltei a Le Thor e procurei o hotel no qual alojamos durante o seminário [...]. [...] não tinha mudado em nada, estava como se eu tivesse acabado de sair, como se, enquanto tudo ao redor se atualizava e se colocava em sintonia com as novas modas e exigências, o tempo naquele ponto tivesse parado. Um minuto mais tarde, compreendi a razão daquilo: o hotel estava em estado de completo abandono, a porta de entrada destruída, a dupla escada que conduzia à porta estava quebrada em vários pontos, o jardim onde tínhamos o seminário, invadido pelo mato. (AGAMBEN, 2017, p.25) ${ }^{8}$

Eis que o incontornável nexo entre vida e lugares se faz presente. O livro, com o pesar da antecipação, termina com uma fotografia par lui-même, intitulada Erba: uma foto colorida do que parece ser um terreno, cujo mato (essa forma de vida que não é senão Deus) tomou conta. Desse modo, procurando concluir com o que seria o rumo de uma vida, de um pensamento, diz Agamben (2017, p.167): "L'erba, l'erba è Dio. Nell'erba - in Dio - sono tutti coloro che ho amato. Per l'erba e nell'erba e come l'erba ho vissuto e vivrò", isto é, "O mato, o mato é Deus. No mato - em Deus - estão todos aqueles que amei. Pelo mato, e no mato, e como mato vivi e viverei" 9 .

Com isso, quem sabe pode-se dizer também que este livro não é senão um livro de confissões: a de seus afetos e fidelidade, que parecem sugerir algo mais do que uma simples promessa a uma potência.

Assim como o título do livro joga com a polissemia, pois pode ser lido tanto como um "autorretrato no estúdio ou no escritório" quanto um "autorretrato através

\footnotetext{
${ }^{8}$ Molti anni dopo, nel 1985, sono tornato a Le Thor e ho cercato l'albergo in cui alloggiavamo durante il seminario [...]. [...] non era mutato in nulla, era come se lo avessi appena lasciato, come se, mentre tutto intorno si aggiornava e metteva al passo delle nuove mode e esigenze, il tempo in quel punto si fosse fermato. Un minuto dopo ne capivo la ragione: l'albergo era in stato di completo abbandono, la porta d'ingresso divelta, la doppia scalinata che conduceva alla porta fracassata in più punti, il giardino dove tenevamo il seminario invaso dalle erbacce.

9 Optei traduzir "erba" por "mato", uma vez que a palavra mais usada no Brasil para falar da relação entre a vegetação que cresce a partir do abandono é "mato";
} 
do estudo"10, a dúplice montagem agambeniana (palavra e imagem), nos permite pensar até que ponto a promessa de Agamben à "Erva-Deus", não é também uma promessa aos seus próprios afetos; e mais: até que ponto a Erba de sua própria fotografia, que retrata várias formas de vida - mato, grama, tremoço, borragem, ervadaninha ou Deus -, não poderia ser, inclusive, o retrato de um passado insistente, que não cessa de aparecer.

Qual seria esse passado-presente que não cessa de retratar Agamben nas folhas deste livro? É um passado que está presente justamente na Erba que põe fim ao livro, e que não é senão a metonímia de um amor e de uma vida que ainda vivem pelos "matos de Le Thor", nos "matos de Le Thor" e como os "matos de Le Thor".

\title{
REFERÊNCIAS
}

AGAMBEN, Giorgio. Autoritratto nello studio. Milano: Nottetempo, 2017.

ANDREOTTI, R. DE MELIS, F. Entrevista com Giorgio Agamben: Analogie e paradigmi. Un'intervista a Giorgio Agamben. Alias, supplemento settimanale de II manifesto, a. 9, n. 35 (420), p. 1-5, 8, 9 set. 2006. Disponível em: $<$ https://haecceitasweb.com/2010/05/27/giorgio-agamben-un-ragionare-perparadigmi/> Acesso em: 30 set. 2017.

. Entrevista com Giorgio Agamben. Tradução para Português de Vinícius N. Honesko. Entrevista publicada em 09/09/2006 no suplemento Alias, do periódico II Manifesto (a. 9, n. 35), p. 1-5. Tradução. Disponível em: <http://flanagens.blogspot.it/2016/01/as-lembrancas-por-favor-nao.html> Acesso em: 30 set. 2017

\author{
Resenha recebida em: 02/10/2017 \\ Resenha aprovada em: 15/11/2017 \\ Resenha publicada em: 18/12/2017
}

\footnotetext{
${ }^{10}$ Studio em italiano é tanto um gabinete de trabalho, um escritório, quanto o verbo "estudar", conjugado na primeira pessoa: estudo. Assim, a leitura possibilita duas compressões: autorretrato no escritório ou autorretrato no estudo.
} 